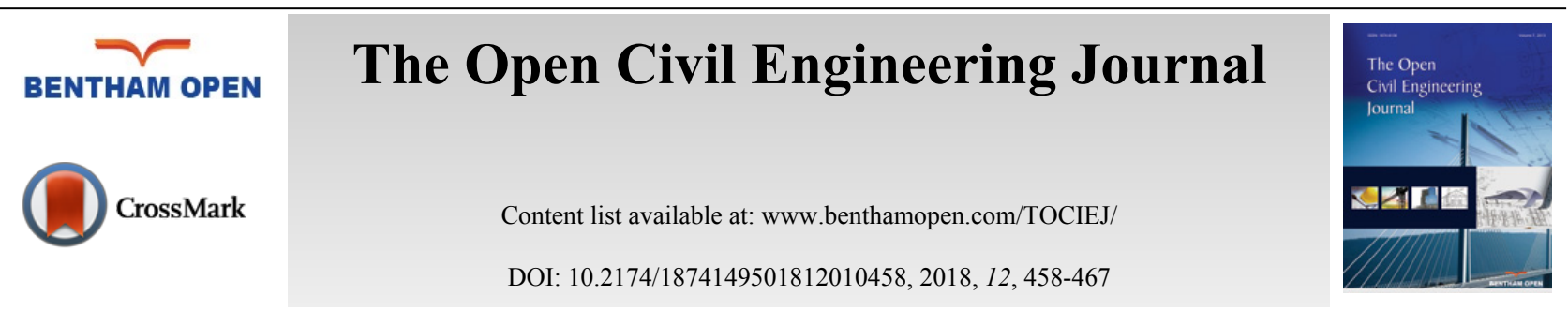

REVIEW ARTICLE

\title{
Change Orders in Iraqi Construction Projects
}

\author{
Hafeth I. Naji ${ }^{1, *}$, Wadhah Amer Hatem ${ }^{2}$ and Baydaa Hussain Maula ${ }^{3}$ \\ ${ }^{I}$ Civil Engineering Department, University of Diyala, Baquba, Iraq \\ ${ }^{2}$ Baquba Technical Institute, Middle Technical University, Baquba, Iraq \\ ${ }^{3}$ Institute of Technology, Middle Technical University, Baghdad, Iraq
}

Received: October 13, 2018

Revised: November 14, 2018

Accepted: November 28, 2018

\begin{abstract}
:
Introduction:

Change orders in construction are considered to be one of the greatest controversial problems that must be handled and also considered to be difficult for project management to reasonably resolve as any variation leads to claims. Any construction contract is agreed under the concept of "good faith," which include that the parties will have to trust each other in order to work on agreeing on a contract and that contract is considered to be reasonable when there is no purpose of taking benefit of the parties throughout the contract life. However, as soon as the contract wants to be changed by generating a change order, the parties behavior changes in relation to the initial "good faith" environment
\end{abstract}

\section{Objective:}

The aim of the paper is to find the causes of the change order and its effect on the projects and then analyze the causes using data mining techniques.

\section{Methods:}

The methodology of the paper includes the following steps. Several factors that lead to change orders were gathered from the literature review. A questionnaire was formed and then distributed to the managers, owners, contractors and engineers. A review of the project's documents was conducted to find the number of change orders in the project and analysis of the causes of the change orders was done using data mining techniques.

\section{Results and Conclusion:}

The change orders have a harmful impact on the cost and it must be minimized, the change order was analyzed using Adda Boost technique and the accuracy was about 95 which is considered a very good result.

Keywords: Change order, Cost, Effect, Adda Boost, Good faith, Environment.

\section{INTRODUCTION}

The construction industry environment is considered to be complex and competitive as enormous parties with various views, abilities and awareness levels work together [1], thus this may lead to change orders. For a long time, the change orders are an integral industry of construction portion. It is rare to find a construction project being implemented without a modification that usually arises as a consequence of some sources that belong to the various parties included in the project implementation. When the change is being recognized, then is officially standardized by the releasing of a change order, that is a document that labels the changing scope and its influence on time and cost both. If no settlement is established between the project parties on the change, it will transfer to a claim or dispute that may harmfully impact

* Address correspondence to this author at the Civil Engineering Department, University of Diyala, Baquba, Iraq; Tel: +964 770 4372844; E-mail: rowedahhussien@gmail.com 
on the implementation of the project and limit its chances to become effective. A number of investigators provided numerous descriptions for a change order. It is a work that is considered new or removed from the original work contract scope that will make changes in the amount of the original contract or date of completion [2].

Change orders in construction are considered to be one of the greatest controversial problems that must be handled and also considered to be difficult for project management to reasonably resolve any variation leading to claims. Any construction contract is agreed under the concept of "good faith," which includes that the parties will have to trust each other in order to work by agreeing on a contract and that a contract is considered to be reasonable when there is no purpose of taking benefit of the parties throughout the contract life. However, as soon as the contract is changed by generating a change order, the parties behavior changes in relation to the initial "good faith" environment [3].

Thus, the aim of the paper is to find the causes of the change order and its effect on the projects and then analyze the causes using data mining techniques.

\section{LITERATURE REVIEW}

Osman et al. [4] suggested that a change is any variation from a decided upon well-known schedule and scope. The phrase "change order" raises the robust mood of constructiveness for everything included in projects of construction. Owners do not prefer them since they commonly feel they are compensating for other's faults. In certain cases, from the point of view of the contractors, the change orders interrupt workflow and need extra paperwork and time. In different cases, contractors would catch the change orders as a method to increase their project outcome. Though, it is usually recognized that consultants, owners, and contractors approve that projects would be better without change orders.

Homaid et al. [5], explored 21 reasons and 11 possible change orders influences, and also, nine practices informed to change orders control and management. The study recognized eleven significant reasons and seven vital influence. It is determined in advance that the consultant is the greatest blamable party for the change orders. The overall average growth in the projects of construction total cost is due to change orders and it is about $11.3 \%$. The research determined that changes in the scope of the project are due to requirements of the owner and this has the greatest significant reason and overruns of cost are the greatest significant influences on change orders in those projects.

A questionnaire survey was used to recognize reasons and influences of changes on projects of construction and create proposals on how changes can be escaped or reduced on upcoming projects [6]. Jawad [7] produced reasons, influence, and controls of change orders in the huge construction of the building. The study decided that the main cause of variation is the owner and that greatest difference is structural and civil. Statistical analysis of reasons for the change in design in highway construction in Taiwan was conducted by $\mathrm{Wu}$ [8]. Olsen [9] studied the greatest mutual reasons for change orders which are work separations and considered them to be the most vulnerable to the largest amount of change orders. It is established that errors in design were accountable for the common changes.

Costs of Swedish housing construction have increased more than the inflation rate through the last decade (1994-2004). In Flyvbjerg's [10] report to the British Department for Transport, he distinguished that transport projects are fundamentally risky because the long planning horizon and composite project interface, that often induces variability associated to hesitate at the initial project stages, technical standards, and conditions of the Geotechnical. Also, the nature that considers split and short-term construction projects combined with many stakeholders with changed purposes makes it hard to accomplish high-level and reliable quality [11].

In this paper, AdaBoost technique was used which is an abbreviation for Adaptive Boosting. It is a meta-algorithm in machine learning founded by Yoav Freund and Robert Schapire. It can be found along with many other kinds of algorithms of learning to increase efficiency. The other algorithms of learning output ('weak learners') are merged into a weighted sum that characterizes the boosted classifier final output [12]. AdaBoost denotes a specific method of training a boosted classifier [12].

$$
F_{T}(x)=\sum_{t=1}^{T} f_{t}(x)
$$

Where every ftis a learner that receives an object $\mathrm{x}$ as input and gives back a value representing the object class [13]. 


\section{METHODOLOGY}

The methodology of the paper (Fig. 1 and Table 1) includes a questionnaire survey to get an indication of the importance of these factors. The distribution of questionnaires was random and the sample was mixed between owners, consultants, and contractors. The steps can be explained as follows:

1. Several factors that lead to change orders were gathered from the Literature review, which include books,researches and other resources.

2. The questionnaire is initially formed and then distributed to the initial population to check its stability,its structure and its relation to the subject.

3. Then the questionnaire is finally distributed owners, consultants, and contractors.

4. The researcher collects data from the projects which are documents that contain the change orders in the projects and the cost of these changes and why these changes occur.

5. Analysis of the causes of the change orders using data mining techniques.

The ORANGE program was used.

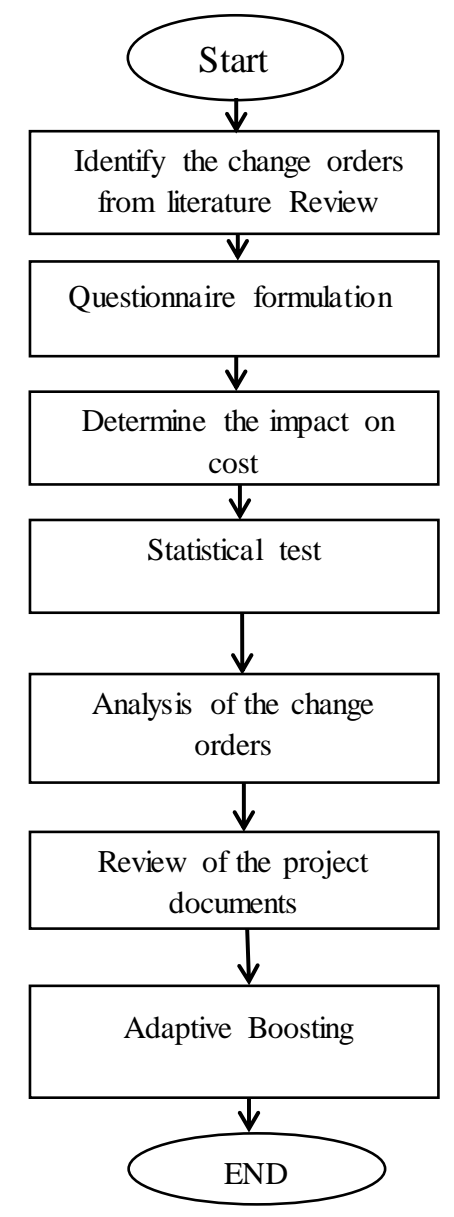

Fig. (1). The methodology of the research.

Table 1. The Norms and Standard for change orders.

\begin{tabular}{|c|c|}
\hline Scale & Numerical \\
\hline Very high & 5 \\
\hline High & 4 \\
\hline Medium & 3 \\
\hline Low & 2 \\
\hline Very low & 1 \\
\hline
\end{tabular}


The measurements that are used to show the effect on the quality and measurement give the response as shown below in Tables $\mathbf{2}$ and $\mathbf{3}$.

Table 2. The Norms and Standard for change order effect on the cost.

\begin{tabular}{|c|c|}
\hline Cost & Effect on cost \\
\hline More than 200 million & Very high \\
\hline $50-200$ million & High \\
\hline $10-50$ million & Medium \\
\hline $3-10$ million & Low \\
\hline Less than 3 million & Very low \\
\hline
\end{tabular}

Table 3. The change orders.

\begin{tabular}{|c|c|}
\hline Change order & Change order \\
\hline C1: Change of plans by owner & C6: Contractor's lack of judgment \\
\hline C2: Errors and omission in design (main element) & C7: Failure by a consultant to perform design and supervision effectively \\
\hline C3: Poor planning by the contractor & C8: New government regulation \\
\hline C4: Owner fails to make decisions or review documents at the right time & C9: Demolition and re-work, Quality improvement. \\
\hline C5: The scope of work for the contractor is not well defined & C10: Safety available at the project site \\
\hline
\end{tabular}

\section{ANALYSIS AND DISCUSSION OF RESULTS}

The first step of change order analysis identifies them by using the questionnaire, it's being distributed over 30 experts who previously worked in the projects The questionnaire was gathered and then formulation of the data, a fivepoint scale as follows: very high, high, medium, low and very low. The impacts were calculated based on the following equation [14].

$$
\operatorname{Mean}(\overline{\mathrm{X}})=\sum_{i=1}^{h} x_{i} \cdot f_{i} / n
$$

Which ( $\overline{\mathrm{X}}$ mean, $\left(X_{i}\right)$ Class Center, $\left(f_{i}\right)$ The number of iterations for each class, $(n)$ ) Total sample size or duplicates of the varieties, (i) Sequence of class, h) number of class.

As a result of the questionnaire of the impact of the claims were determined. The second step was used some statistical test using the ORANGE program (Fig. 2).

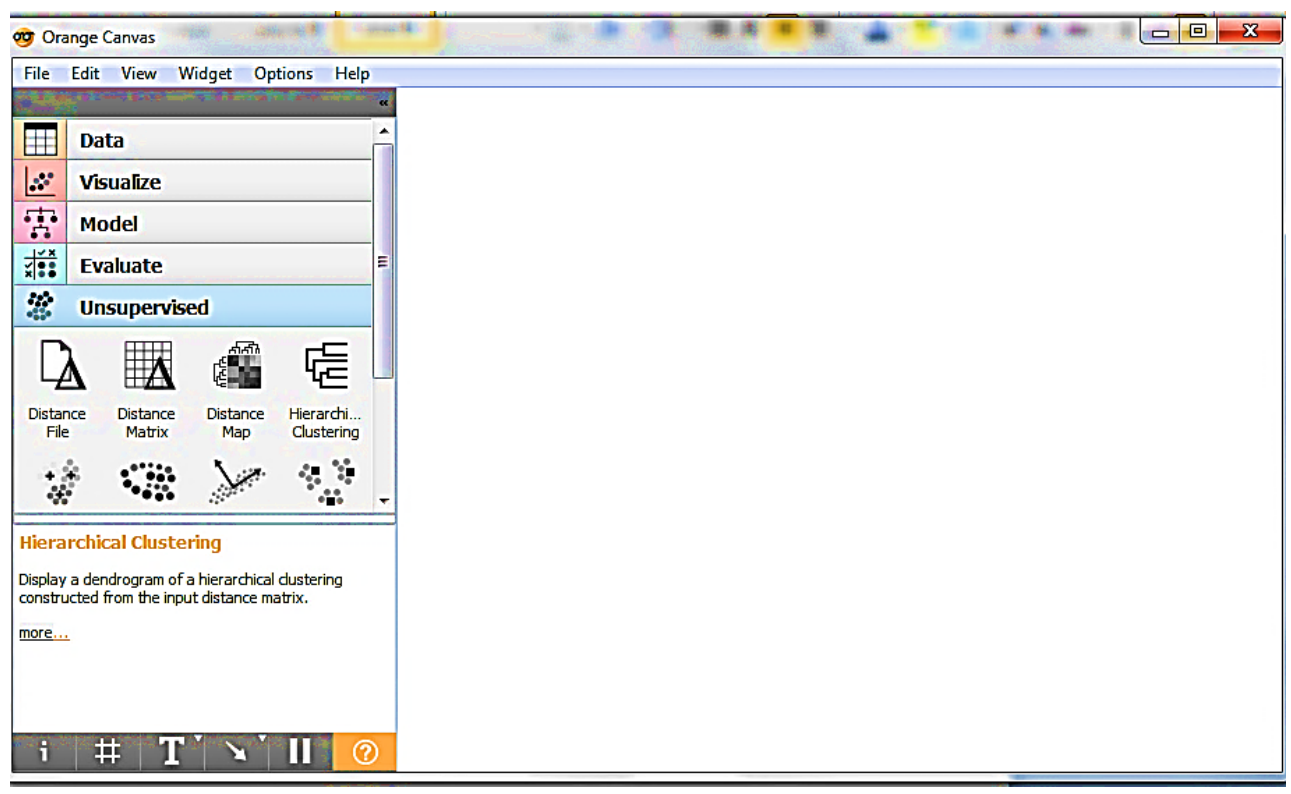

Fig. (2). The main interface of the program. 
The Fig. (3) below shows the distribution of the projects and the cost.

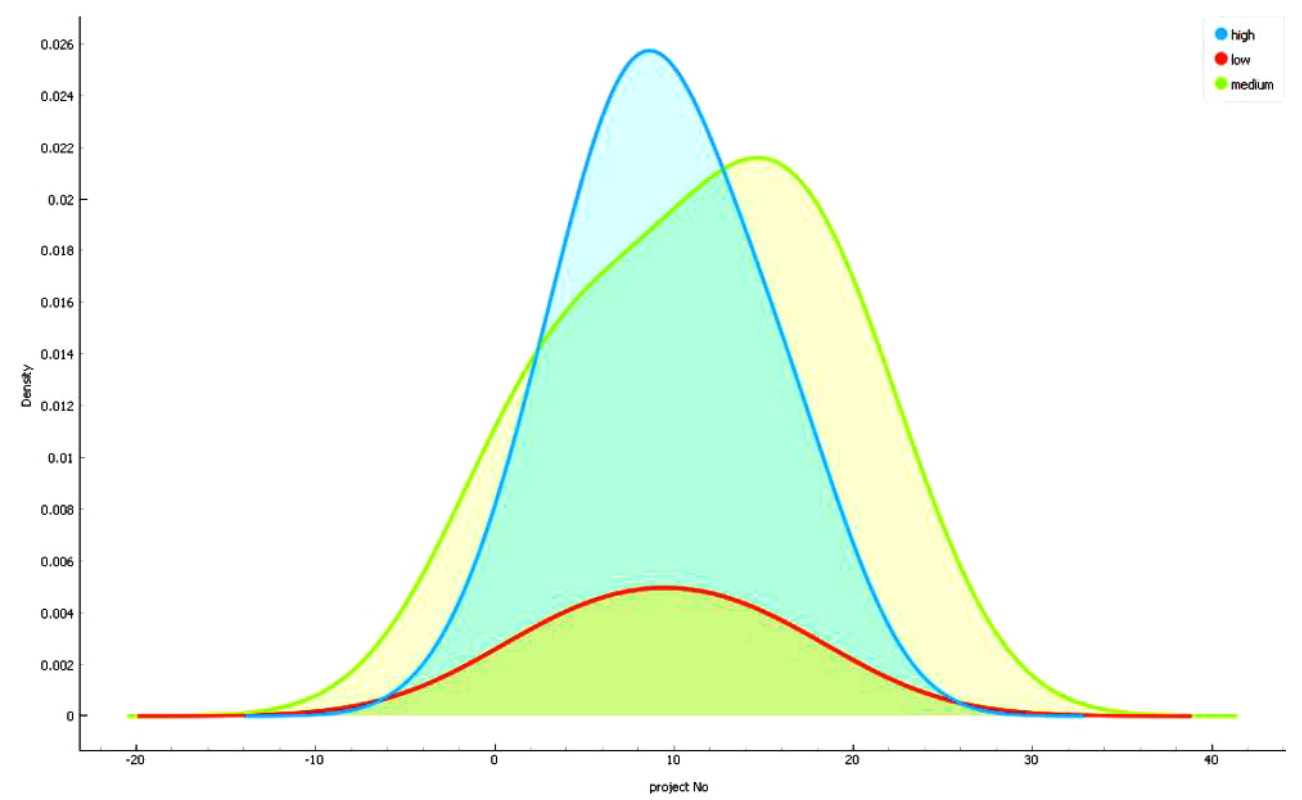

Fig. (3). Distribution of the projects.

The above Fig. (4) shows that the projects are normally distributed.

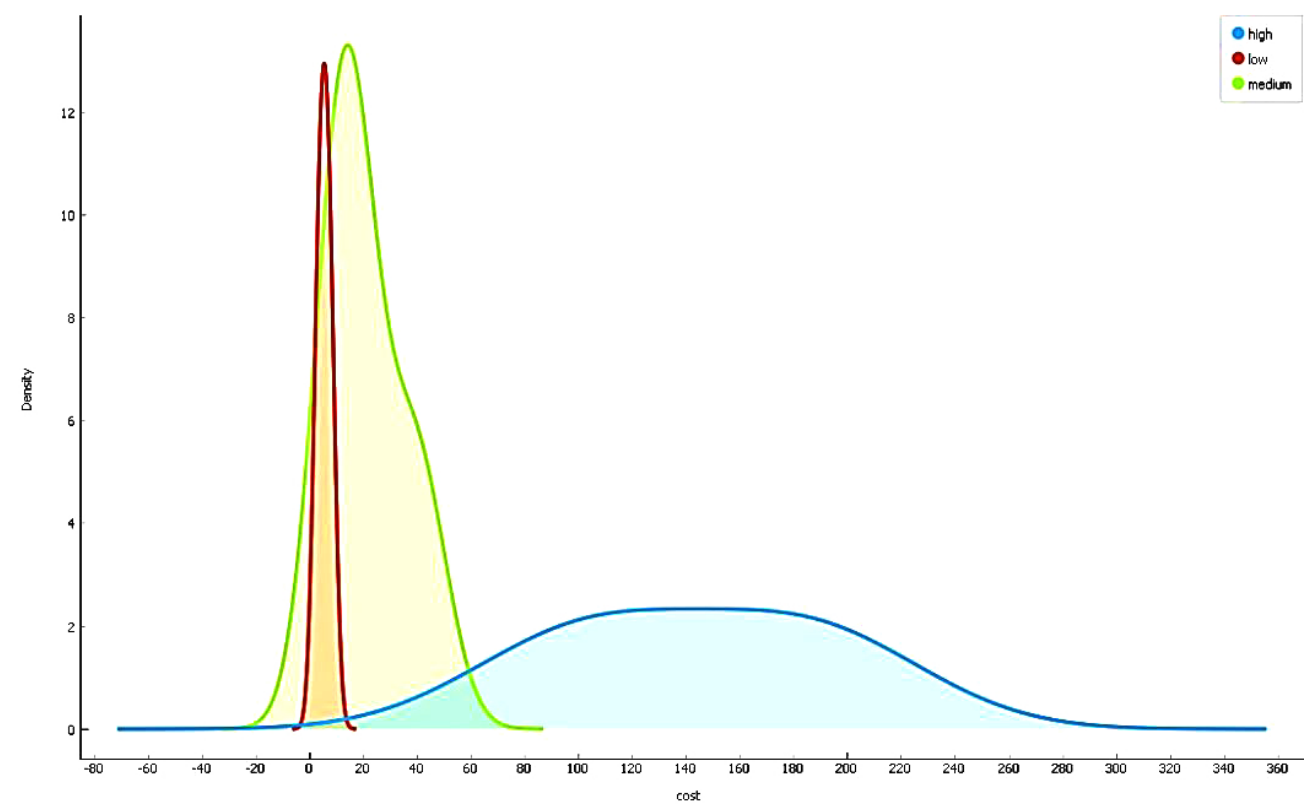

Fig. (4). Distribution of the cost of the projects.

Several tests were used like PCA for future extraction. PCA is Principal Component Analysis (PCA) which in many ways practices the foundation analysis of multivariate data. PCA offers an estimate of a data table, a data matrix, X, in terms of the product of two small matrices T and P' (Fig. 5) [15].

Another test was used which is called MDS. Multidimensional Scaling (MDS) is a technique which discovers a lowdimensional (in our case a two-dimensional) pointed projection, where it attempts to find suitable distances among points as close as possible. The flawless fit is classically impossible to find since the data considered is highdimensional or the distances are not Euclidean (Fig. 6) [16]. 


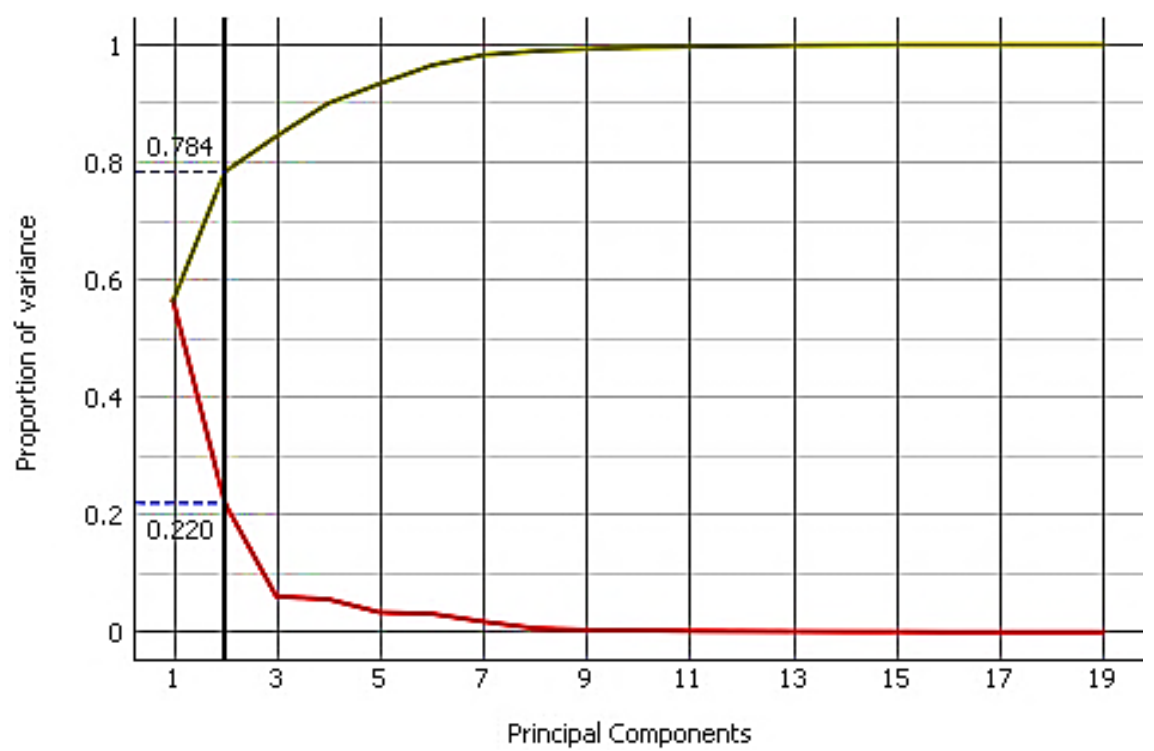

Fig. (5). PCA test.

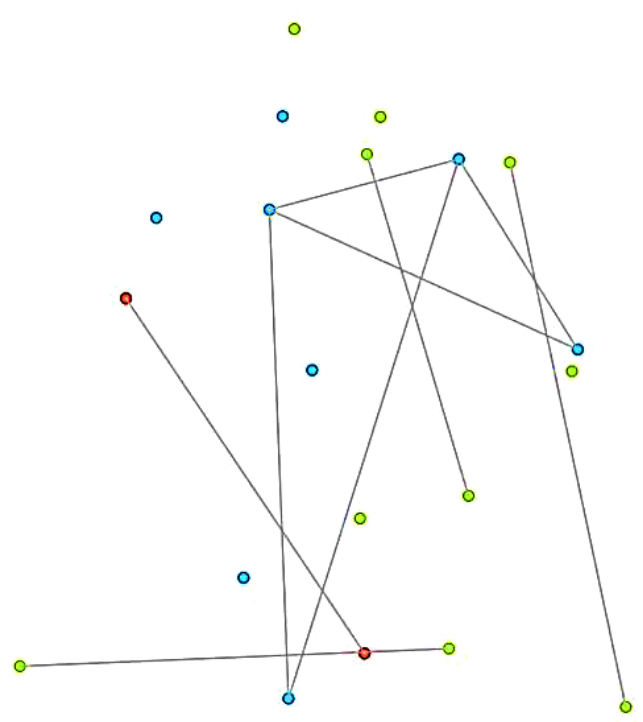

Fig. (6). MDS test.

After the statistical test, the change orders in the projects were determined as shown in the table below Table 4 .

Table 4. Show the change orders effects.

\begin{tabular}{|c|c|c|c|}
\hline Projects & Change Order & Projects & Change Order \\
\hline 1 & $\begin{array}{c}\text { 1-Ordinary concrete for walks } \\
\text { 2-Processing of materials and dye with a paint } \\
\text { 3-Processing of materials and packaging with ceramic tiles for facades } \\
\text { 4-Material processing and packaging of stone for the facades } \\
\text { 5-Processing of materials and packaging of the floor and sides of the stairs } \\
\text { mirrors } \\
\text { 6-Processing of materials and work of secondary ceilings } \\
\text { 7-Focus glaze with cement mortar } \\
\text { 8-Processing materials and whitewash with plaster } \\
\text { 10-Bentonite pigment } \\
\text { 11-Concrete concretes for bridges } \\
\text { 12-Reinforced concrete ceilings } \\
\text { 13-Two opposite layers of Kair } \\
\text { 14-The tiling of the cutter }\end{array}$ & 11 & $\begin{array}{l}\text { 1-Fuzzy delete } \\
\text { 2-Prose works } \\
\text { Concrete works } \\
\text { 3-Plastic pipe fitting }\end{array}$ \\
\hline
\end{tabular}




\begin{tabular}{|c|c|c|c|}
\hline Projects & Change Order & Projects & Change Order \\
\hline 2 & $\begin{array}{l}\text { 1-Prepare the material and do the cleaning of the site, with skimming the } \\
\text { upper soil and moving it to hallowed places } \\
\text { 2-The processing of materials and the burial of successful mosaic under the } \\
\text { floors } \\
\text { 3-Ordinary concrete using floor-resistant cement } \\
\text { 4-Ordinary concrete using cement resistant to walkways } \\
\text { 5-Concrete concretes for bridges of all floors } \\
\text { 6-Reinforced concrete for interior and exterior stairs } \\
\text { 7-Construction of the blocks above the exchange for all floors } \\
\text { 8-Whiteness with plaster }\end{array}$ & 12 & $\begin{array}{l}\text { 1-Vibrio cement } \\
\text { 2-White plaster } \\
\text { 3-Ceramic application }\end{array}$ \\
\hline 3 & $\begin{array}{l}\text { 1-Concrete for exchanges } \\
\text { 2-Building blocks for partitions }\end{array}$ & 13 & $\begin{array}{l}\text { 1-Liquor Cement } \\
\text { 2-Outdoor cooking fumes } \\
\text { 3-The tubs }\end{array}$ \\
\hline 4 & $\begin{array}{l}\text { 1-Material processing and faking work for facades and mold removal } \\
\text { 2-Equipment processing and demolition of old buildings }\end{array}$ & 14 & $\begin{array}{c}\text { 1-Fuzzy delete } \\
\text { 2-Prose works } \\
\text { Concrete works } \\
\text { 3-Plastic pipe fitting }\end{array}$ \\
\hline 5 & $\begin{array}{l}\text { 1-Brush layer brushes } \\
\text { 2-Aluminum Works } \\
\text { 3-Florence Double F2 } \\
\text { 4-Go to the stairs of the Dosa stairs with a distance of } 1.8 * 0.3 \mathrm{~m} \\
\text { 5-For the stairs of the stairs with a height of } 1.8 * 0.17 \mathrm{~m} \\
\text { 6-Take a phone }\end{array}$ & 15 & $\begin{array}{l}\text { 1-Taking capacity } 13 \\
\text { 2-The introduction of a copper cable } 4 * 35 \\
\text { 3-Works of Tulsa }\end{array}$ \\
\hline 6 & $\begin{array}{l}\text { 1-Liquor Cement } \\
\text { 2-Arranging workshops and setting the floor under the floors }\end{array}$ & 16 & $\begin{array}{l}\text { 1-Stone packaging } \\
\text { 2-Processing of cameras }\end{array}$ \\
\hline 7 & $\begin{array}{l}\text { 1-The processing of successful burial materials under the floors } \\
\text { 2-Secondary ceilings } \\
\text { 3-Burial in clean soil } \\
\text { 4-Ordinary Concrete Flooring } \\
\text { 5-Liquor Cement } \\
\text { 6-Exterior of the Alabaster } \\
\text { 7-Applying to the Macchi delete }\end{array}$ & 17 & $\begin{array}{l}\text { 1-Prepare the material and do the cleaning of the site, } \\
\text { with skimming the upper soil and moving it to } \\
\text { hallowed places } \\
\text { 2-Arranging workshops and setting the floor under } \\
\text { the floors } \\
\text { 2-Concrete Flooring }\end{array}$ \\
\hline 8 & $\begin{array}{l}\text { 1-Processing materials and carrying out the installation of a } 15 \mathrm{~cm} \\
\text { 2-Planning and drilling all kinds of foundations } \\
\text { 3-Reinforced concrete ceilings }\end{array}$ & 18 & $\begin{array}{l}\text { 1-Liquor Cement } \\
\text { 2-Materials processing and dyeing of bennetlite }\end{array}$ \\
\hline 9 & $\begin{array}{l}\text { 1-Vibrio cement } \\
\text { 2-White plaster } \\
\text { 3-Ceramic application }\end{array}$ & 19 & $\begin{array}{l}\text { 1-Vibrio cement } \\
\text { 2-White plaster } \\
\text { 3-Ceramic application }\end{array}$ \\
\hline 10 & $\begin{array}{l}\text { 1-Grounding the foundation aspects } \\
\text { 2-Construction with solid floors under the paddle }\end{array}$ & 20 & $\begin{array}{l}\text { 1-Grounding the foundation aspects } \\
\text { 2-Construction with solid floors under the paddle }\end{array}$ \\
\hline
\end{tabular}

After that the reasons for change order analysis (Table 5 and Figs. 7-11).

Table 5. The change orders cost in the projects.

\begin{tabular}{|c|c|c|c|}
\hline Project & Change Order Cost & Project & Change Order Cost \\
\hline 1 & 10286000 & 11 & 122000000 \\
\hline 2 & 185466720 & 12 & 43950000 \\
\hline 3 & 13200000 & 13 & 34952000 \\
\hline 4 & 11924000 & 14 & 3861000 \\
\hline 5 & 7310000 & 15 & 197230000 \\
\hline 6 & 197230000 & 16 & 13200000 \\
\hline 7 & 92573000 & 17 & 111861000 \\
\hline 8 & 87362750 & 18 & 16000000 \\
\hline 9 & 39720000 & 19 & 15000000 \\
\hline 10 & 163500000 & 20 & 15000000 \\
\hline
\end{tabular}




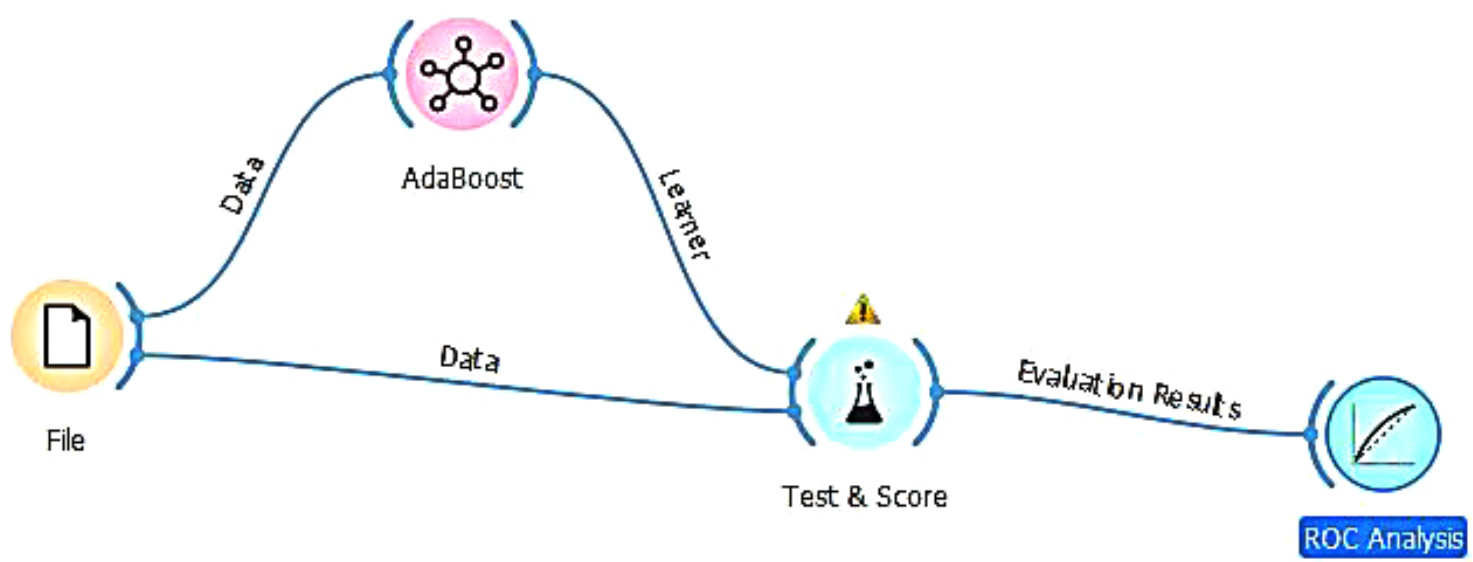

Fig. (7). workflow.

\section{Settings}

Sampling type: 10 -fold Cross validation

Target class: Average over classes

\section{Scores}

$\begin{array}{llllll}\text { Method } & \text { AUC } & \text { CA } & \text { F1 } & \text { Precision } & \text { Recall } \\ \text { AdaBoost } & & 0.950 & 0.800 & 0.667 & 1.000\end{array}$

Fig. (8). Accuracy of technique.

The accuracy was 95 and it is considered a very good result.

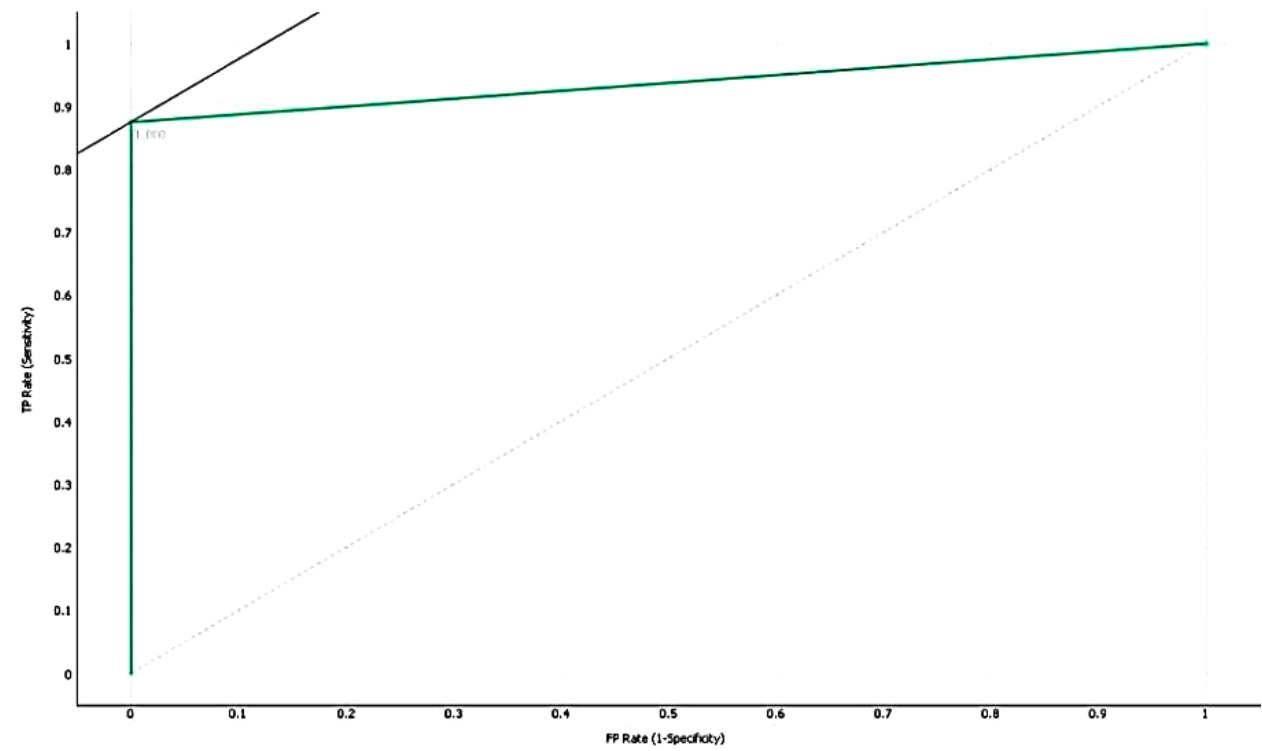

Fig. (9). ROC of high class. 


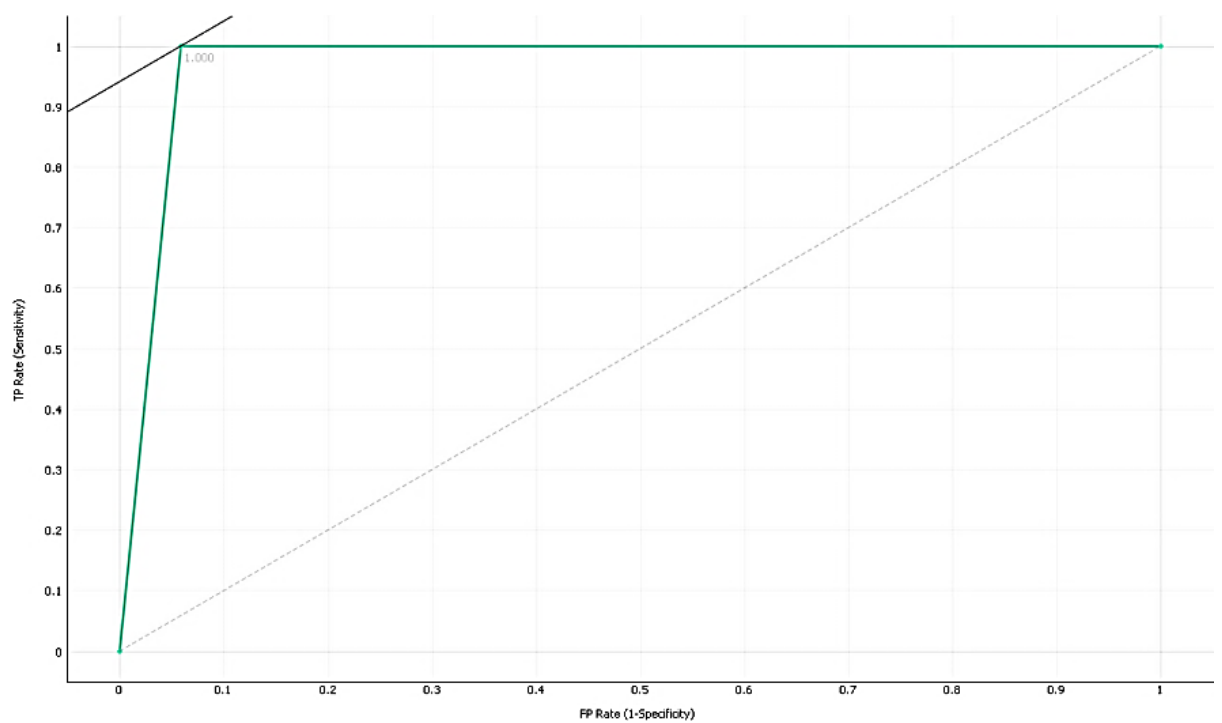

Fig. (10). ROC of medium class.

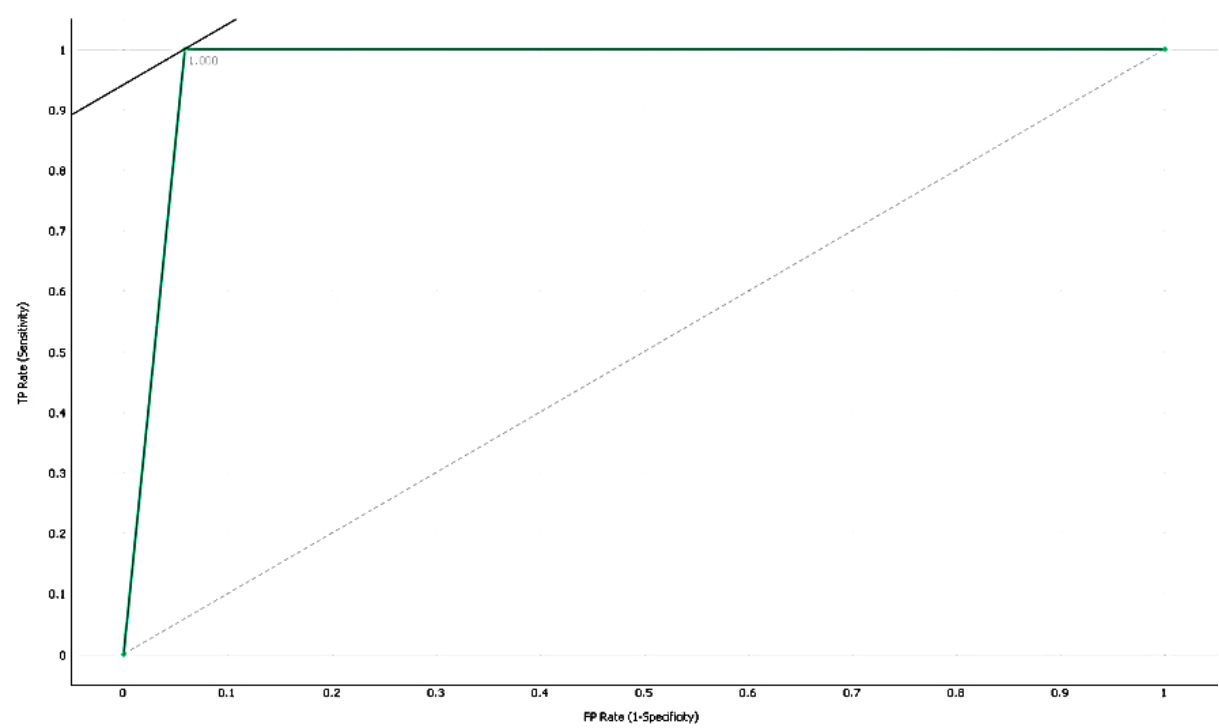

Fig. (11). ROC of low class.

\section{CONCLUSION}

The change order has a harmful impact on the cost as it increases the cost and hence it must be removed.

Vibrio cement and whiteness with plaster are considered the most repeated change orders in the projects and tend to increase the cost significantly. Overall, the most repeated items that need variation are finishing items and it is due to three reasons, firstly the owner changes his mind about the requirement, and secondly there is special condition on the site that requires additional finishing or repeats the finishing, and thirdly due to the demolition and re-work, quality improvement requires work without ny error.

Concrete works and bricks change orders, return to the errors and oversight in design (main element), poor planning by the contractor and contractors lack judgment are the main reasons for the change order. Another reason for change is that the owner fails to make decisions or review documents at the correct time. The work scope for the contractor is not well known due to failure of consultant in performing design and supervision effectively and new government regulation.

The change order was analyzed using Adda Boost technique and the accuracy was about 95 which is considered a very good result. 


\section{CONSENT FOR PUBLICATION}

Not applicable.

\section{CONFLICT OF INTEREST}

The authors declare no conflict of interest, financial or otherwise.

\section{ACKNOWLEDGEMENTS}

The researcher expresses his sincere thanks to the Ministry Of Higher Education and Scientific Research (MOHESR) and the University of Thi-Qar for the general support provided to achieve the scientific research.

\section{REFERENCES}

[1] C. Khekale, and N. Futane, "Management of claims and disputes in the construction industry", Int. J. Sci. Res. (Ahmedabad), vol. 5, no. 5, pp. 848-846, 2015.

[2] N. Zawawi, N. Azman, and M. vs, "Sustainable construction practice: A review of change orders in construction projects", International Conference on Environment, 13-15 Dec. Pulau, 2010.

[3] R. Soares, "Change orders ordeal: The output of project disintegration", Int J Busin, Human Tech, vol. 2, no. 1, pp. 65-69, 2012.

[4] Z. Osman, A. Omran, and C.K. Foo, "The potential effects of variation orders in construction projects", J. Eng. (Stevenage), vol. 2, pp. $141-152,2009$.

[5] N. Homaid, A. Eldosouky, and M. Alghamdi, "Change orders in saudi linear construction projects", Emirates J Eng Res, vol. 16, no. 1, pp. 33-42, 2010.

[6] P. Keane, B. Sertyesilisik, and A. Ross, "Variations and change orders on construction projects", J. Leg. Aff. Dispute Resolut. Eng. Constr., vol. 2, no. 2, pp. 89-96, 2010.

[http://dx.doi.org/10.1061/(ASCE)LA.1943-4170.0000016]

[7] R. Jawad, R. Abdulkader, and A. And Ali, "Variation orders in construction projects", J. Eng. Appl. Sci. (Asian Res. Publ. Netw.), vol. 4, no. 3, pp. 170-176, 2009.

[8] C. Wu, T. Hsieh, and W. Cheng, "Statistical analysis of causes for a design change in highway construction on Taiwan", Int. J. Proj. Manag., vol. 23, pp. 554-563, 2005. [http://dx.doi.org/10.1016/j.ijproman.2004.07.010]

[9] B. Flyvbjerg, M.K. Skamris Holm, and S.L. Buhl, "How common and how large are cost overruns in transport infrastructure projects?", Transp. Rev., vol. 23, no. 1, pp. 71-78, 2003. [http://dx.doi.org/10.1080/01441640309904]

[10] A. Toakley, and M. Marosszeky, "Towards total project quality - A review of research needs", Eng. Construct. Architect. Manag., vol. 10, no. 3, pp. 219-228, 2003.

[http://dx.doi.org/10.1108/09699980310478467]

[11] D. Olsen, R. Killingsworth, and P. Brandon, "Change order causation; Who is the guilty party", $48^{\text {th }}$ ASC Annual International Conference Proceedings, pp. 1-9, 2012.

[12] B. Kégl, "The return of AdaBoost", MH: Multi-class Hamming trees, 2013.

[13] M. Sobhi, A.S. Adnan, and M. A. Awad, Introduction to statistics House Joan and Elie and his sons, 1983.

[14] G.F. Hughes, "On the mean accuracy of statistical pattern recognizers", IEEE Trans. Inf. Theory, vol. 14, no. 1, pp. 55-63, 1968. [http://dx.doi.org/10.1109/TIT.1968.1054102]

[15] F. Wood, K. Esbensen, and P. Geladi, "Principal component analysis", Chemometr. Intel. Lab. Syst, pp. 37-52, 1987.

[16] F. Wickelmaier, "An introduction to MDS. Sound quality research unit", Aalborg University. , 2003. Available from: https://homepage.unituebingen.de/florian.wickelmaier/ pubs/Wickelmaier2003SQRU.pdf

\section{(C) 2018 Naji et al.}

This is an open access article distributed under the terms of the Creative Commons Attribution 4.0 International Public License (CC-BY 4.0), a copy of which is available at: https://creativecommons.org/licenses/by/4.0/legalcode. This license permits unrestricted use, distribution, and reproduction in any medium, provided the original author and source are credited. 